\title{
Wheezing Beyond Bronchial Asthma
}

\author{
Pant P., Sharma S., Shrestha R., Bom N., Das S. , Yogi K. N. \\ Respiratory Unit, Department of Internal Medicine, Tribhuvan University Teaching Hospital, Nepal.
}

Correspondence to: Pankaj Pant, T.U.T.H, Kathmandu, Nepal.

Email: drpant77@hotmail.com

\begin{abstract}
Churg-Strauss syndrome (CSS) is an eosinophil-associated, small vessel granulomatous vaculitis, characterized by late onset asthma, upper airways disease, eosinophilia, and clinical manifestations of systemic vasculitis. [1,11-13] Diagnosis is mainly clinical with findings of asthma, eosinophilia, rhino sinusitis and signs of vasculitis in major organs. So far to the best of our knowledge reporting of CSS has not been done in Nepal. We here present a case of ChurgStrauss syndrome, a Anti-Neutrophil Cytoplasmic Antibody(ANCA) Associated Vasculities more specifically perinuclear anti-neutrophil cytoplasmic antibodies (p-ANCA) directed against myeloperoxidase (MPO) in a 25years female patient who was initially evaluated for progressive dyspnea, wheeze, cough, joint pain and fever. Regarding the inference drawn from our case report we suggest that patient presenting with the clinical features of asthma needs further evaluation to unmask previously unrecognized underlying Churg-stauss syndrome.
\end{abstract}

Key Words: Churg Strauss Syndrome, Asthma , ANCA associated Vasculitis, Young adult female.

\section{Introduction}

Churg Strauss syndrome(CSS) was first described by Drs. Jacob Churg (1910-2005) and Lotte Strauss (1913-1985) at Mount Sinai Hospital in New York City in 1951.[2] CSS is a systemic inflammatory disease characterized by asthma, eosinophilia, and involvement of various organ systems such as the upper and lower respiratory tract, the peripheral nervous system, the skin, the kidney and the gastrointestinal tract. Histology of CSS usually discloses small-vessel vasculitis, eosinophil-rich infiltrates and eosinophilic granulomas. Because of the frequent positivity of antineutrophil cytoplasmic antibodies (ANCAs), which are found in $30-40 \%$ of the cases, and the predominant involvement of small vessels, CSS has been grouped with microscopic polyangiitis (MPA) and granulomatosis with polyangiitis (Wegener's) (GPA) under the umbrella term 'ANCA-associated vasculitis' (AAV).[3] Among the three anti-neutrophil cytoplasmic antibodies (ANCA)associated vasculitis, CSS is least common, [4] with an estimated annual incidence of between 1 and 3 cases per million people.[7-10]ANCApositive patients usually show a more vasculitic phenotype,[5,6]although the vasculitis is often not apparent in the initial phases of the disease. It is important to recognize this disease clinically and beware of missing diagnosis as classic histology is barely found and is also not confirmatory for diagnosis. But the disease has distinctive clinical presentation and criteria developed which reflect its importance. It is important to diagnose the disease and monitor for relapse as it is frequent and requires immediate attention. Here, we present a case of Churg-Strauss syndrome in a 25yrs female who was initially evaluated as adult onset asthma. With this case report of a young adult female, we'll like to suggest clinicians that not all wheezes are mere bronchial asthma but could be a telltale sign of ominous vasculitis and also with diagnosis long term follow up is needed as asthma, at least of moderate severity typically pre-dates the onset of vasculitis by several years.

\section{Case Report}

A 25 years female presented to the TUTH emergency with the history of progressive short of breath, dry cough for 2 weeks, low grade continuous fever and joint pain especially 
small joints of hands and knee joints for 1 month. There was on and off history of throat irritation, itchy eyes and runny nose. There was a history of itchy erythematous rashes especially during summer season. There was no history of asthma, drug allergy, parasitic infestation and no prior history of similar illness. Her menstrual history was normal. She was non smoker and non alcohol consumer. Her parents had no such symptoms. On examination there was $1000 \mathrm{~F}$ fever, tachypnea with other vital parameters normal. There was pallor, Conjunctival suffusion and few excoriated rashes however there was no icterus, clubbing, cyanosis, lymphadenopathy or edema.

On respiratory examination there was bilateral normal vesicular breath sounds with prolonged expiration with expiratory wheeze. Other systemic examination was within normal limit. On investigation regarding blood parameters, there was anemia(Hbg;8.6Gm\%), leucopenia(WBC;2300/cmm), raised ESR(72mm/hr), eosinophilia( 20\% eosinophilis), ANA positive, P-ANCA positive, CRP positive with other parameters within normal limit. Chest X-ray and USG abdomen was normal.

So with the clinical features of progressive dyspnea, fever, joint pain, expiratory wheeze, and investigation findings of raised eosinophils, ANA positive, P-ANCA positive, raised CRP we made diagnosis of ANCA associated vasculitis, "Churg strauss syndrome".

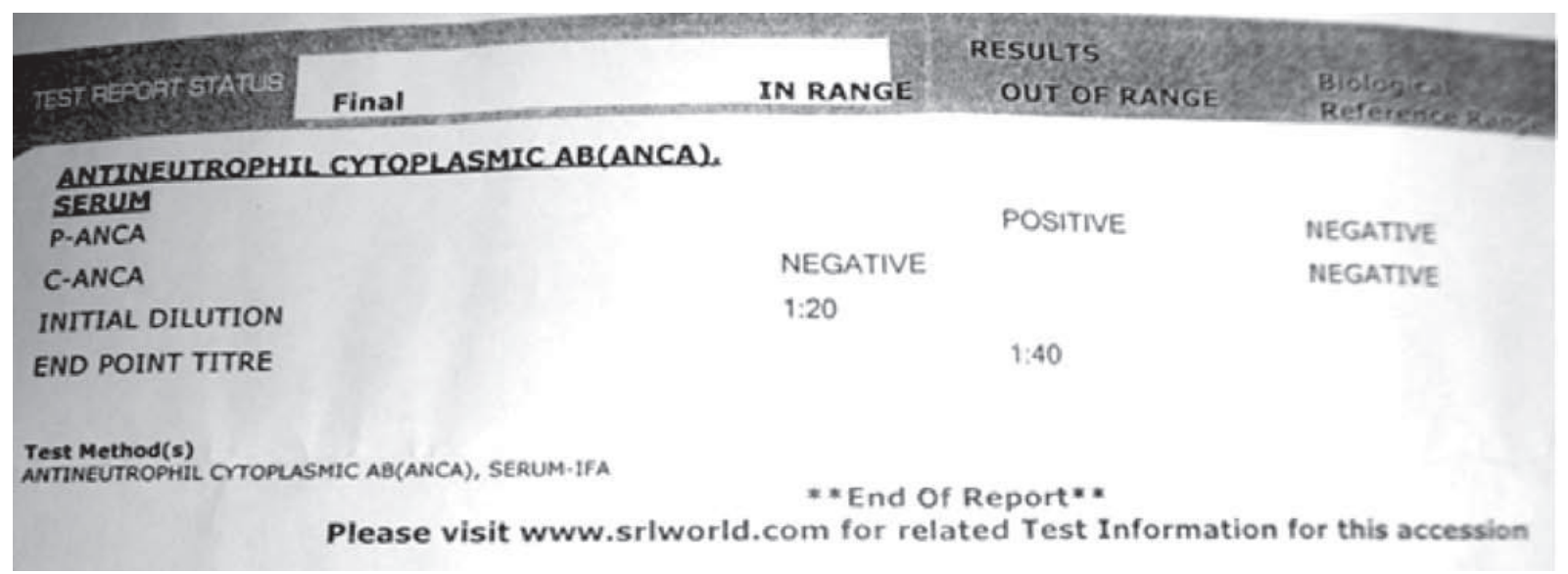

Fig.1 Lab report of the same patient showing P-ANCA positive

\section{Discussion}

The Churg-Strauss syndrome (CSS), also called allergic granulomatosis and angiitis, is a multisystem disorder characterized by allergic rhinitis, asthma, and prominent peripheral blood eosinophilia. Among the three anti-neutrophil cytoplasmic antibodies (ANCA)-associated vasculitis, CSS is least common, [4] with an estimated annual incidence of between 1 and 3 cases per million people[7-10]. The mean age at diagnosis of CSS is 40 years. [15] However our case is of 25years old female which is rare encounter. CSS does not exhibit gender predominance.[15,16] CSS is unknown in origin. Suggestions are allergic or immune mediated. Etiology is considered to be autoimmune due to allergic symptoms, immune complex mediation 48\% are (ANCA, antineutrophil cytoplasmic antibody) positive, increased T-cell mediated immunity, elevated immunoglobulin E (IgE) levels and rheumatoid factor. [14]

The clinical course of CSS usually evolves through three phases: the prodromic, 'allergic' phase, hallmarked by asthma, allergic rhinitis, and sinusitis; the second, 'eosinophilic' phase, with peripheral eosinophilia and clinical features due to tissue eosinophilic infiltration (for example, eosinophilic gastroenteritis); the third, also called 'vasculitic,' with manifestations of necrotizing vasculitis (for example, peripheral neuropathy and purpura).[3] Churg-Strauss syndrome can involve almost any organ. The frequencies of its clinical features are reported in Table 1.[4-6] 
Table 1. Frequencies of the main clinical manifestations of Churg-Strauss syndrome in three large series of patients

\begin{tabular}{|c|c|c|c|c|}
\hline$\cdot$ & $\begin{array}{c}\text { Keogh and Specks }{ }^{|4|} 91 \\
\text { patients }\end{array}$ & Sinico et al. ${ }^{[6]} 93$ patients & $\begin{array}{c}\text { Sablé-Fourtassou et al. }{ }^{[5]} 112 \\
\text { patients }\end{array}$ & Main clinical features by organ system \\
\hline Asthma & $99 \%$ & $96 \%$ & $100 \%$ & . \\
\hline $\begin{array}{l}\text { Nasal and paranasal } \\
\text { sinus involvement }\end{array}$ & $74 \%$ & $77 \%$ & $62 \%$ & Rhinitis, sinusitis, nasal polyps \\
\hline Lung involvement & $58 \%$ & $51 \%$ & $\begin{array}{l}\text { Infiltrates, } 65 \% \text {;pleural effusion, } 22 \% \text {; } \\
\text { alveolar hemorrhage, } 7 \%\end{array}$ & $\begin{array}{l}\text { Migratory pulmonary infiltrates, pleural } \\
\text { effusion, alveolar hemorrhage }\end{array}$ \\
\hline $\begin{array}{l}\text { Constitutional } \\
\text { symptoms }^{\text {a }}\end{array}$ & NA & $68 \%$ & $\begin{array}{l}\text { Weight loss, } 8 \% \text {; fever, } 45 \% \text {; } \\
\text { arthralgia, } 37 \% \text {; myalgia, } 54 \%\end{array}$ & . \\
\hline Skin manifestations & $57 \%$ & $53 \%$ & $52 \%$ & Purpura, nodules, urticarial lesions \\
\hline $\begin{array}{l}\text { Peripheral nervous } \\
\text { system involvement }\end{array}$ & $76 \%$ & $65 \%$ & $72 \%$ & $\begin{array}{l}\text { Mononeuropathy, mononeuropathy multiplex, } \\
\text { distal symmetric polyneuropathy }\end{array}$ \\
\hline $\begin{array}{l}\text { Gastrointestinal } \\
\text { manifestations }\end{array}$ & $31 \%$ & $22 \%$ & $32 \%$ & $\begin{array}{l}\text { Abdominal pain, digestive hemorrhage, } \\
\text { diarrhea }\end{array}$ \\
\hline Kidney involvement & $25 \%$ & $27 \%$ & $16 \%$ & $\begin{array}{l}\text { Urinary abnormalities, rapidly progressive } \\
\text { renal failure }\end{array}$ \\
\hline Heart involvement & $13 \%$ & $16 \%$ & $35 \%$ & Cardiomyopathy, pericarditis \\
\hline $\begin{array}{l}\text { Central nervous } \\
\text { system involvement }\end{array}$ & $11 \%$ & $14 \%$ & $9 \%$ & $\begin{array}{l}\text { Cranial nerve palsy, cerebral infarction or } \\
\text { hemorrhage }\end{array}$ \\
\hline
\end{tabular}

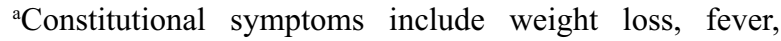
fatigue, diffuse arthralgia, and myalgia.

Clinical diagnosis is based on American College of Rheumatology Criteria which requires the presence of four or more of these six clinical criteria in the setting of vasculitis suggests the presence of Churg-Strauss syndrome (CSS) with a sensitivity of $84 \%$ : asthma, eosinophilia $>10 \%$, neuropathy, migratory or transient pulmonary opacities, abnormalities of the paranasal sinuses and extravascular eosinophils on biopsy. [13] Asthma is crucial to the diagnosis and is relatively late in age of onset. As in our case, patient had no prior history of symptoms suggestive of asthma till the age of 25years. Histological diagnosis is by demonstration of vasculitis that is necrotizing, tissue infiltration with eosinophils and extra-vascular granulomas are found in a few cases.[1]. Regarding radiology, the most consistent radiological findings are lobular or centrilobular peripheral consolidation and nodularity, thickened bronchial walls, inter-lobular septum, and peri-cardial and pleural effusion. [17] On computed tomography, enlargement of or distortion of peripheral pulmonary arteries may be seen. The ultimate diagnosis is by biopsy with open biopsy preferred to TBLB( Transbronchial Lung Biopsy) or sural nerve sampling in case of symptoms.[18] However in our case we didn't opt for biopsy as clinical features and lab reports were highly suggestive of CSS.

The differential diagnosis includes Wegener's granulomatosis, microscopic polyangitis, Hypereosinophilic syndrome, Chronic eosinophilic pneumonia, drug reaction, bronchogenic granulomatosis, fungal and parasitic infections, malignancy, immune mediated diseases such as idiopathic thrombocytopenic purpura, cryoglobulenemia, and collagen vascular diseases. Complications are mostly drug related and due to disease activity so long term follow up is vital.

The first step in the management of CSS is to assess the severity of disease. A frequently used system is the "fivefactors score" (FFS) based on the presence or absence of five clinical factors: cardiac involvement, gastrointestinal disease, renal insufficiency (plasma creatinine concentration $>1.6 \mathrm{mg} / \mathrm{dL}$ [141 micromol/L]), proteinuria (>1 g/day), or central nervous system involvement.[21] The fivefactor score stratifies patients into low-risk and highrisk categories. [21] [22] Those with a five-factor score $\geq 1$ require an escalation in immunosuppressant therapy. Although remission is achieved in $>80 \%$ of patients, CSS is commonly a relapsing disease $(10 \%$ to $43 \%)$. Flares secondary to vasculitis must be distinguished from asthmatic 
flares, because they require different treatment. Minimising adverse effects of treatments is a further important goal of therapy.

The prognosis of this disease has improved dramatically since the introduction of corticosteroids, and they remain the first line of therapy of Churg-Strauss syndrome (CSS).

Treatment regularly is with prednisone starting at 40-60 $\mathrm{mg}$ a day and the occasional addition of cyclophosphamide or azathioprine with the purpose to limit the disease or spare steroids. [19] In our case we treated the patient with $60 \mathrm{mg}$ prednisone a day. In case of fulminant disease or multi-organ involvement, parenteral corticosteroid such as methylprednisolone is used. If response to mentioned treatment is not seen, parenteral immunoglobulin is administered. The B-cell-depleting monoclonal antibody rituximab, now a key treatment option for many autoimmune diseases including GPA and MPA, has been tried in a number ofCSS cases refractory to conventional immunosuppression. $[23,24,25 \cdot, 26-29]$ In most CSS cases rituximab induced symptom remission with significant decrease in eosinophil counts. Many different organ manifestations responded to the addition of rituximab, that is central nervous system lesions,[29] renal abnormalities, [25•] skin lesions[27] and respiratory disease.[28]Prospective studies are now needed to assess its long-term efficacy and safety in CSS. In sporadic cases, other agents such as mycophenolate mofetil, intravenous immunoglobulins, TNFa-blockers and other immunosuppressants have been reported to be beneficial in CSS patients, but no clear evidence yet supports their use.[30] Finally, plasma exchange is also one of the most widely used treatments for AAV, particularly in cases with lifethreatening manifestations such as alveolar haemorrhage or rapidly progressive glomerulonephritis;[31] although no systematic data are available on CSS, this procedure should be considered in CSS cases with severe vasculitic manifestations.

Regarding aforementioned treatment modalities, conventional therapies with glucocorticoids and immunosuppressant's remain the standard of care for CSS, newer agents directed against specific cytokines might be used in the future. But still management remains a challenge, with limited clinical trials.

\section{Conclusion}

Adult young female with shortness of breath, wheeze, allergic rhinosinusitis, more specifically acute onset of moderate to severe adult onset asthma as in our case should be evaluated thoroughly to rule out CSS. Though definite diagnosis may not be always possible in country like ours with minimal resources however what we like to recommend is CSS can be diagnosed clinically with the aid of few supportive lab investigations. So physicians should be vigilant for clinical signs and clinical presentation. Early diagnosis and intervention as required will certainly help to preclude possible complications in such patients and once diagnosed long term follow up is needed as relapse is frequent and requires immediate attention.

\section{References}

1. Lanham JG, Elkon KB, Pusey CD, et al. Systemic vasculitis with asthma and eosinophilia: a clinical approach to the Churg-Strauss syndrome. Medicine 1984; 63: $65 \pm 81$.

2. Churg J, Strauss L (1951). “Allergic granulomatosis, allergic angiitis, and periarteritis nodosa". Am. J. Pathol. 27 (2): 277-301.

3. Pagnoux C, Guilpain P, Guillevin L. Churg-Strauss syndrome. Curr Opin Rheumatol 2007; 19:25-32.

4. Keogh KA, Specks U. Churg-Strauss syndrome. Semin Respir Crit Care Med 2006; 27:148.

5. Sable-Fourtassou R, Cohen P, Mahr A, et al. Antineutrophil cytoplasmic antibodies and the Churg Strauss syndrome. Ann Intern Med 2005; 143:632638.

6. Sinico RA, Di Toma L, Maggiore U, et al. Prevalence and clinical significance of antineutrophil cytoplasmic antibodies in ChurgStrauss syndrome. Arthritis Rheum 2005; 52:29262935.

7. Watts RA, Carruthers DM, Scott DG. Epidemiology of systemic vasculitis: changing incidence or definition? Semin Arthritis Rheum. 1995;25:28-34.

8. Watts RA, Lane SE, Bentham G, et al. Epidemiology of systemic vasculitis: a ten-year study in the United Kingdom. Arthritis Rheum. 2000;43:414-419.

9. Gonzalez-Gay MA, Garcia-Porrua C, Guerrero J, et al. The epidemiology of the primary systemic vasculitides in northwest Spain: implications of the Chapel Hill Consensus Conference definitions. Arthritis Rheum. 2003;49:388-393.

10. Reinhold-Keller E, Herlyn K, Wagner-Bastmeyer R, et al. Stable incidence of primary systemic vasculitides over five years: results from the German vasculitis register. Arthritis Rheum. 2005;53:93-99.

11. Guillevin L, Cohen P, Gayraud M, Lhote F, Jarousse B, Casassus P. Churg-Strauss syndrome: 
clinical study and long-term follow-up of 96 patients. Medicine 1999;78: 26 \pm 37 .

12. Cottin V, Cordier J-F. Churg-Strauss syndrome. Allergy 1999; 54: 535 \pm 551 .

13. Masi AT, Hunter GG, Lie JT, et al. The American College of Rheumatology 1990 criteria for the classifiacation of Churg-Strauss syndrome (allergic granulomatosis and angiitis). Arthritis Rheum 1990; 33: 1094 \pm 1100 .

14. Gross WL, Reinhold-Keller E: Churg-Strauss Syndrome. [http://www.orpha.net/data/patho/GB/ukCSS.pdf] webcite Orphanet Encyclopedia 2002, 1-7.

15. Conron M, Beynon HL. Churg-Strauss syndrome. Thorax 2000; 55:870.

16. Harrold LR, Andrade SE, Go AS, et al. Incidence of Churg-Strauss syndrome in asthma drug users: a population-based perspective. J Rheumatol 2005; 32:1076.

17. Jeong YJ, Kim K, Seo IJ, et al.: Eosinophilic lung diseases: a clinical radiologic, and pathologic overview. Radiographics 2007, 27:617- 637.

18. Semple D, Keogh J, Forni L, et al.: Clinical review: vasculitis in the intensive care unit-part 2: treatment and prognosis. Critical Care 2005, 9:193 197.

19. Fallah Tafti S, Mansouri D, Masjedi MR, Marashian M, Faridian D: Churg Strauss syndrome after introducing oral steroid to inhaler-a report of three cases. Iran J Allergy Asthma Immunol June 2006, 5(2):89-94.

20. Semple D, Keogh J, Forni L, et al.: Clinical review: vasculitis on the intensive care unit-part 1: diagnosis. Critical Care 2005, 9:92-97.

21. GuillevinL, Lhote F,Gayraud M,et al. Prognostic factors in polyarteritis nodosa and Churg-Strauss syndrome. A prospective study in 342 patients. Medicine (Baltimore) 1996; 75:17.

22. Bourgarit A, Le Toumelin P, Pagnoux C, et al. Deaths occurring during the first year after treatment onset for polyarteritis nodosa, microscopic polyangiitis, and Churg-Strauss syndrome: a retrospective analysis of causes and factors predictive of mortality based on 595 patients. Medicine (Baltimore). 2005;84:323330.

23. Roccatello D, Sciascia S, Rossi D, et al. Long-term effects of rituximab added to cyclophosphamide in refractory patients with vasculitis. Am J Nephrol 2011; 34:175-180.

24. Pepper RJ, Fabre MA, Pavesio C, et al. Rituximab is effective in the treatment of refractory ChurgStrauss syndrome and is associated with diminished T-cell interleukin-5 production. Rheumatology (Oxford) 2008; 47:1104-1105.

25. Cartin-Ceba R, Keogh KA, Specks U, et al. Rituximab for the treatment of ChurgStrauss syndrome with renal involvement. Nephrol Dial Transplant 2011. [Epub ahead of print]•An interesting series of three CSS patients with renal involvement treated with rituximab for refractory disease.

26. Jones RB, Ferraro AJ, Chaudhry AN, et al.A multicenter survey of rituximab therapy for refractory antineutrophil cytoplasmic antibodyassociated vasculitis. Arthritis Rheum 2009; 60:21562168.

27. Kaushik VV, Reddy HV, Bucknall RC. Successful use of rituximab in a patient with recalcitrant ChurgStrauss syndrome. Ann Rheum Dis 2006; 65:11161117.

28. Koukoulaki M, Smith KG, Jayne DR. Rituximab in Churg-Strauss syndrome. Ann Rheum Dis 2006; 65:557-559.

29. Saech J, Owczarczyk K, Rosgen S, et al. Successful use of rituximab in a patient with Churg-Strauss syndrome and refractory central nervous system involvement. Ann Rheum Dis 2010; 69:1254-1255.

30. Pagnoux C. Churg-Strauss syndrome: evolving concepts. DiscovMed 2010; 9:243-252.

31. Casian A, Jayne D. Plasma exchange in the treatment of Wegener's granulomatosis, microscopic polyangiitis, Churg-Strauss syndrome and renal limited vasculitis. Curr Opin Rheumatol 2011; 23:1217. 